\title{
Assessing the Usability of Online Food Ordering Websites Using a New Fuzzy Kano Method: Implications for Improvement
}

\author{
Arshia Taimouri ${ }^{1}$, Korosh Emamisaleh ${ }^{2}$ \& Davoud Mohammadi ${ }^{3}$ \\ ${ }^{1}$ Department of Management, University of Ershad Damavand, Tehran, Iran \\ ${ }^{2}$ Department of Industrial Management, Islamic Azad University South Tehran Branch, Tehran, Iran \\ ${ }^{3}$ Department of Management, Islamic Azad University South Tehran Branch, Tehran, Iran \\ Correspondence: Arshia Taimouri, Department of Management, University of Ershad Damavand, Tehran, Iran. \\ E-mail: arshiateimouri@gmail.com
}

Received: June 8, 2019

doi:10.5539/ijbm.v14n10p87
Accepted: August 10, $2019 \quad$ Online Published: September 5, 2019

URL: https://doi.org/10.5539/ijbm.v14n10p87

\begin{abstract}
Following the rapid development of the Internet, e-commerce websites are widely used today for various goals. An essential point in the prosperity of these websites is their level of usability. Accordingly, measuring this usability is indispensable for these websites to check whether they are moving in the right path. Thus, in this article, the usability scores of five well-known online food-ordering websites in Iran have been evaluated using a novel fuzzy Kano method with respect to design parameters. In addition to assessing usability scores, the design parameters of these websites have been classified and reviewed in a detailed manner in order to determine the design priorities of these websites as one of the main results of this study. Data were gathered using a questionnaire with 190 respondents. Results demonstrated that Snappfood is the best online food-ordering website in Iran. In addition, sorting restaurants based on customer satisfaction score, using high-quality images of foods along with the image zooming feature, and the existence of complete information about foods and restaurants are the most effective and important design parameters of these types of websites according to the findings of this study.
\end{abstract}

Keywords: Website usability; Online food-ordering websites; Website design parameters; Fuzzy Kano model

\section{Introduction}

Following the quick growth of the Internet, online businesses have seriously joined the world market over the last one or two decades and are expected to flourish considerably in the near future. Given that customers are primarily able to contact with an online business through its website, the development of a usable website is fundamental and critical for the prosperity of these newcomers in the world of business (Cyr, Head, Larios, \& Pan, 2009; Tung, Xu, \& Tan, 2009). In the scope of the human-computer interaction (HCI) science, usability is a cardinal concept (Díaz, Rusu, \& Collazos, 2017) which has been defined in various ways. A task-oriented definition is whether a task can be accomplished conveniently and rapidly by users (Redish, 1995). According to the ISO9241 (Guidance on Usability), usability is defined as the "effectiveness, efficiency, and satisfaction with which specified users can achieve goals in particular environments" (Standardization, 1998). In websites, usability can be defined as the extent to which it is uncomplicated to have a journey through the website (Stewart, 2012). In addition, Nielsen and Molich (1990) determined some specific features for usable websites, such as the convenience of learning how to use and memorize something, effectiveness for use, ease of understanding, and providing customer satisfaction. So far, researchers have proved that a usable website generates a pleasant image of online stores in the minds of customers, enhances the percentages of revisits and, eventually, promotes online shopping (Casaló, Flavián, \& Guinalíu, 2008; Nielsen, 1999; Venkatesh \& Agarwal, 2006). It is worth noticing that for e-commerce websites, assessing the usability of a website is needed to understand the effect of website design on the purchases of customers (Ilbahar \& Cebi, 2017). Aside from the definitions, some researchers have demonstrated the merits of usability for both individuals and organizations. For people, a decrease in mistakes, acquisition of a positive opinion, and having more propensity for applying computers in the next consumption behavior are the main advantages. For organizations, the reduction of expenses, amelioration of performing responsibilities, and more productivity are the major effects (Venkatesh \& Agarwal, 2006; Legris, Ingham, \& Collerette, 2003; McCloskey, 2006; Venkatesh, Morris, Davis, \& Davis, 2003). Constantly evaluating the 
usability of a product is indispensable to ensuring that it works properly based on the determined targets and does not create any trouble for customers during the consumption period. In fact, the main goal of these evaluations is to examine the bond between the customers and the product to understand whether customers are able to learn and apply it for reaching their goals (Davis \& Jiang, 2016). On the other hand, these days around the world a considerable number of people are using online food ordering websites to order their meals that this trend necessitates a more accurate investigation of these types of websites. Moreover, to date almost no study has evaluated the usability nor identified the major design parameters of these websites. Hence, this study aims to evaluate the usability of some well-known and successful online food-ordering websites (startups) in Iran according to customers' demands (regarding design parameters) and a new method which is a combination of Kano model and fuzzy sets. Generally, this research attempts to answer the following questions:

- Based on the customers' expectations, what features should be considered for designing a usable online food ordering website?

- Based on the customers' expectations, what features are not necessary and should not be considered for designing a usable online food ordering website?

Ultimately, this article is structured as follows: A summary of startups' condition in Iran and the studies pertaining to usability and website usability are presented in the literature review Section. Then the methodology of research which is based on traditional Kano model and fuzzy sets is described. Implementation, results, discussion, managerial implications, and conclusion are presented in the final sections.

\subsection{Startups in Iran}

Hart (2012) defines a startup as "a company or a human institution that is built on different branches and that spontaneously arises the condition of extreme uncertainty, has at its core innovation to create products and services which they wish revolutionize the market". Startups play pivotal roles in today's competitive markets. The founders of these startups are usually young people who own novel and creative ideas and embrace the related risks for generating a new business to revive the economy of a country. Although the idea behind a startup could be a game changer, their survival is not guaranteed since the market of startups is an uncertain market. Remaining creative and innovative, not only about providing products and services but also in the management of the company, are other challenges that startups are encountered (Moroni, Arruda, \& Araujo, 2015). Over the last decade and due to the development of Internet infrastructure, startups in Iran have commenced their activity and are flourishing considerably. Some famous startups in Iran are Digikala (an online retailer similar to Amazon) and Sheypoor (a customer-to-customer marketplace similar to eBay). However, in this study, we have focused on five startups (Chilivery, Reyhoon, Snappfood, Changal, and Delino) which are active in online food-ordering market.

\subsection{Website Usability}

Generally speaking, website usability is defined as the extent to which it is straightforward to work with a website. A substantial number of studies are conducted to assess the usability of different websites by various methods. The majority of past studies mainly focused on websites pertaining to healthcare, government, universities, and libraries. Verkijika and De Wet (2018) evaluated the governmental websites of 31 African countries. Based on some usability characteristics, namely online services, user help, navigation, legitimacy, information architecture, the authors concluded that the studied websites had an unacceptable level of usability, with the average score of $36.2 \%$ and the best score of $64.8 \%$. Along with usability, the credibility of some e-government websites was evaluated in some studies, with results showing a positive relationship between these two factors (Huang \& Benyoucef, 2014). Also, Karaim and Inal (2019) employed heuristic evaluation and studied the usability and accessibility of some governmental websites of Libya. Surprisingly, results demonstrated that these websites had several fundamental usability problems. In the area of academic websites, an overwhelming number of studies have been conducted so far. In one of the most recent studies of this kind, Manzoor, Hussain, Sohaib, Hussain, and Alkhalaf (2019) analyzed the usability of different university websites in various countries and applied six usability metrics, including layout, simplicity, navigation, organization, communication, and content. Eventually, they found that the evaluated websites were not able to meet students' demands regarding usability standards. Moreover, Roy, Pattnaik, and Mall (2014) utilized two evaluation methods, the first one based on a questionnaire and the second one based on performance, to measure the usability of three academic websites. They used the WAMMI questionnaire and the Remote Usability testing technique for evaluations. Related to the area of education and academia, some researchers analyzed the usability of a university's website from a novel aspect. For example, Menzi-Çetin, Alemdağ, Tüzün, and Yıldız (2017) aimed to make the usage of a university website more convenient for students with disabilities (weak eyesight). 
To this end, first they interviewed six students with weak eyesight to grasp which website they desired to use and subsequently performed the usability test. Finally, they provided some tips for ameliorating the usability and design of the university website under study to make it more applicable for the noted group of students. Several studies have been conducted in the domain of healthcare. In one study, the usability of Obamacare website was evaluated according to some usability dimensions such as home page, hardware and software, scrolling, screen, and user experience. Researchers also provided useful tips for assessing the usability of different websites, particularly healthcare websites (Venkatesh, Hoehle, \& Aljafari, 2017). In another study, the usability of a relevant website was measured by increasing the tendency of amphetamine consumers for using online remedy. Participants in this study were both health experts and amphetamine consumers and supplied valuable information about the usability of websites and improvement areas (Hirakis, Casey, \& Clough, 2017). Aside from the aforementioned areas, some researchers concentrated on the usability evaluation of B2C websites. Studies in this area include the assessment of the usability of a well-known e-commerce website in Portugal incorporating visually handicapped users (Gonçalves, Rocha, Martins, Branco, \& Au-Yong-Oliveira, 2018), evaluation of four e-commerce websites in Turkey along with employing a novel method for evaluation (Ilbahar \& Cebi, 2017), and assessment of the usability of B2C websites in China ( $\mathrm{Li} \& \mathrm{Li}, 2011$ ). To sum up, the issue of website usability and its evaluation has extensively been studied by previous researchers. However, the usability assessment of online food-ordering websites has been neglected by previous studies which is the main goal of this study. Besides, in this study, the priorities pertaining to the design of online food-ordering websites will be delineated.

\subsection{Kano Model and Fuzzy Set Theory}

Traditionally, previous scholars considered a linear relationship between the fulfillments of quality characteristics and customer satisfaction (Violante \& Vezzetti, 2017). Along with the challenges and arguments related to this assumption, KANO (1984) proposed a two-dimensional nonlinear model for the classification of product features (Fig. 1). In this model, the horizontal axis depicts the level of fulfillment of an attribute and the vertical axis shows the level of customer satisfaction. The questionnaire of Kano model incorporates two types of questions: functional questions (when an attribute is present) and dysfunctional questions (when an attribute is absent) regarding each attribute of the product or service. Respondents should answer questions based on these options: 1) like, 2) must be, 3) neutral, 4) live-with, and 5) dislike. Subsequently, according to the responses of the customers and by applying the Kano evaluation table (Table 1), each quality attribute will be classified into one of the following categories:

- Must-be (M): While the absence of this attribute induces considerable dissatisfaction, its presence does not enhance customer satisfaction since customers believe this type of attribute is an inseparable feature of a product and its presence is indispensable.

- One-dimensional (O): If an attribute in this category is not fulfilled, it causes dissatisfaction and its presence results in satisfaction proportionally. In fact, the better this attribute is fulfilled, the more satisfied the customers will be.

- Attractive (A): Although lack of fulfillment of attractive attributes does not generate dissatisfaction, their fulfillment creates dramatic customer satisfaction.

- Reverse (R): Attributes in this category should be removed from a service or product immediately as their presence causes dissatisfaction.

- Indifferent (I): The existence or non-existence of this kind of attribute does not affect customer satisfaction or dissatisfaction.

- Questionable (Q): This parameter shows that either the respondent has provided an illogical answer or the question has been explained in a vague manner.

Hence, in order to increase customer satisfaction, " $M$ " should be fulfilled undoubtedly; " $O$ " should be presented in the best way; and in today's competitive world of businesses applying " $A$ " is an excellent strategy to beat other rivals. In addition, since " $R$ " generates customer dissatisfaction, it should be evaded, and in order to curb costs, 'I" should be removed (Lin, Yeh, \& Wang, 2015).

For the first time, Klir and Yuan (1996) introduced the fuzzy set theory to address the ambiguity of human thought. In the literature, fuzzy sets and Kano model have been amalgamated (Ilbahar \& Cebi, 2017). In one study, Florez-Lopez and Ramon-Jeronimo (2012) submitted a model, including Kano model and fuzzy sets, to manage the logistics of customer service more properly. Moreover, Wang (2013) applied the fuzzy Kano model to identify product attributes in order to satisfy customers in the scope of designing a new product. 
Table 1. The evaluation table of Kano's model

\begin{tabular}{cccccc}
\hline \multirow{2}{*}{ Functional } & $\begin{array}{c}\text { Dysfunctional } \\
\text { Like }\end{array}$ & Must-be & Neutral & Live-with & Dislike \\
\hline Like & $\mathrm{Q}$ & $\mathrm{A}$ & $\mathrm{A}$ & $\mathrm{A}$ & $\mathrm{Q}$ \\
Must-be & $\mathrm{R}$ & $\mathrm{I}$ & $\mathrm{I}$ & $\mathrm{I}$ & $\mathrm{M}$ \\
Neutral & $\mathrm{R}$ & $\mathrm{I}$ & $\mathrm{I}$ & $\mathrm{I}$ & $\mathrm{M}$ \\
Live-with & $\mathrm{R}$ & $\mathrm{I}$ & $\mathrm{I}$ & $\mathrm{I}$ & $\mathrm{M}$ \\
Dislike & $\mathrm{R}$ & $\mathrm{R}$ & $\mathrm{R}$ & $\mathrm{R}$ & $\mathrm{Q}$ \\
\hline
\end{tabular}

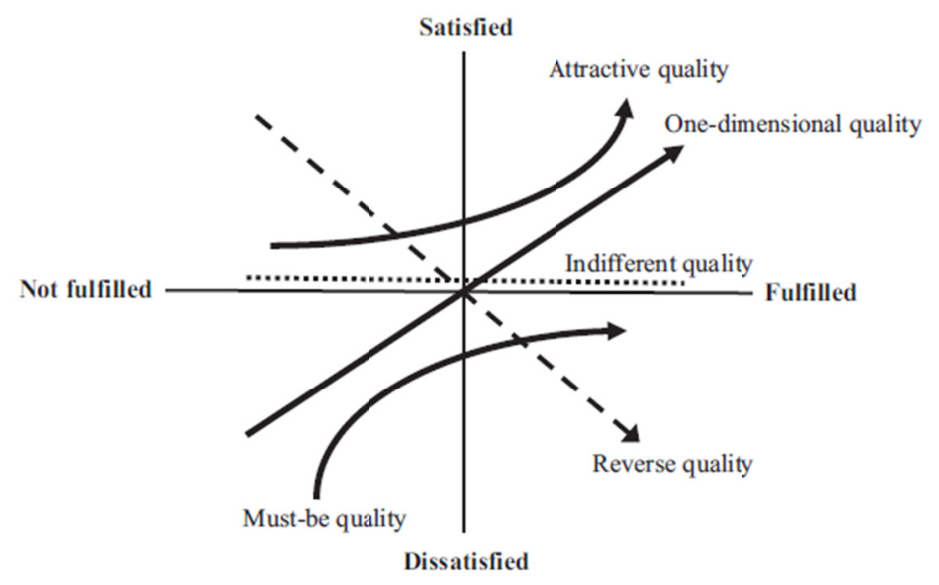

Figure 1. Kano's model (Satisfaction-Fulfillment)

\section{Method}

\subsection{Introducing the New Approach}

Although the Kano method is a precious and rewarding tool for recognizing the real requirements and preferences of customers, it has certain downsides. The traditional questionnaire of Kano method asks respondents to choose one answer from among the alternatives (like, must-be, neutral, live-with, and dislike) and disregards the fact that human thinking coexists with uncertainty (Lee \& Huang, 2009). In addition, another demerit of Kano model is that the frequency of a class is the main factor for determining the class of each parameter/attribute. For instance, suppose that 150 respondents answered a pair of questions in Kano questionnaire and the values of A, M, O, I, R, and Q were 60,59,20,10, and 1, respectively. Consequently, the class of this parameter/attribute would be $\mathrm{A}$ as it has the highest value. Although 59 respondents have decided this parameter as M, only 1 respondent determined the class of this attribute. Accordingly, Ilbahar and Cebi (2017) believed that this part of Kano model requires fuzzification and each attribute should be defined such that it would demonstrate to what extent it belongs to each class. It is evident that this attitude to fuzzy sets and Kano model is different from the confounding and arduous method in the literature which demands respondents to agree with the options based on percentages. In fact, in the present study, the new fuzzy Kano approach (Fig. 2) proposed by Ilbahar and Cebi (2017) has been employed in order to assess the usability of online food-ordering websites and specify their design parameters. The steps of this approach are briefly explained below:

1. For further evaluations, the major design parameters of selected websites are identified through comprehensive research.

2. According to the identified parameters, a questionnaire is designed and distributed among respondents.

3. After calculating the values of A, O, M, I, R, and Q Based on the primary results obtained from the questionnaire, the parameters' weights are computed via the below equations. If $(A+O+M)>(I+R+Q)$ holds, Equation (1) is used; otherwise, equations (2) and (3) are employed.

$$
\begin{gathered}
W i=A+O / A+2 \times O+M \text { for } i \in\{A, O, M\} \\
W i=0 \text { for } i \epsilon\{I\}
\end{gathered}
$$




$$
W i=-R / I+R+Q \text { for } i \epsilon\{R\}
$$

4. In this step, normalized values must be calculated by dividing the responses to a special class by the whole number of responses.

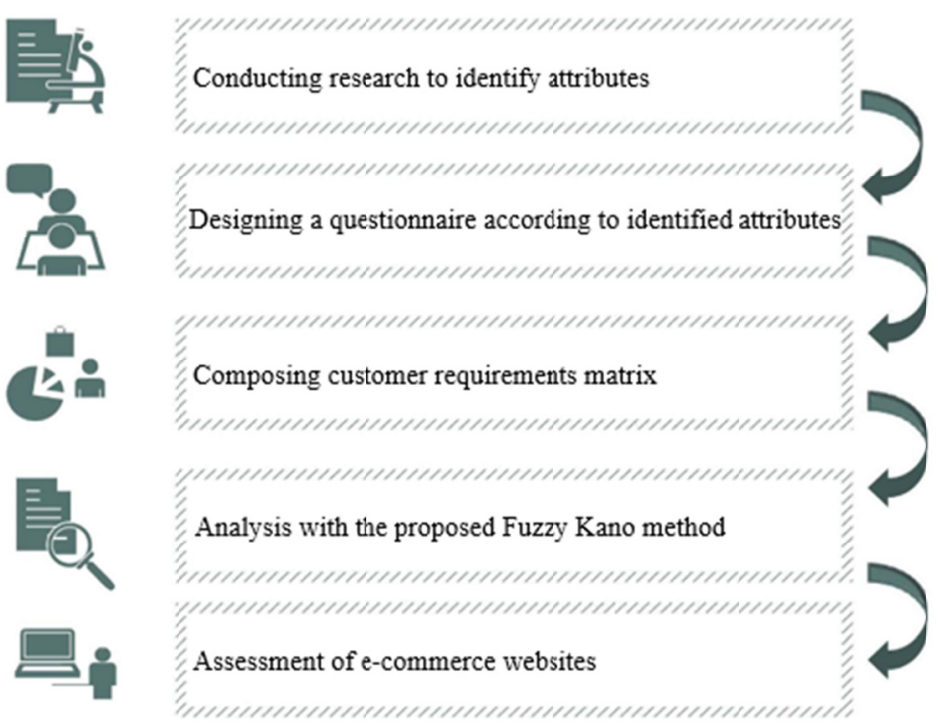

Figure 2. Major levels of the proposed approach

Source: (Ilbahar and Cebi, 2017).

5. The normalized values of each class "M-O-A" or "Q-R-I" belonging to each parameter are placed on a graph called the center of gravity graph (Fig. 3). Next, this graph should be defuzzified with the formula of center of gravity represented in equation (4) to assign each parameter's class.

$$
\operatorname{COG}(F)=\int_{X}^{-} x F(x) d x / \int_{X}^{-} F(x) d x
$$

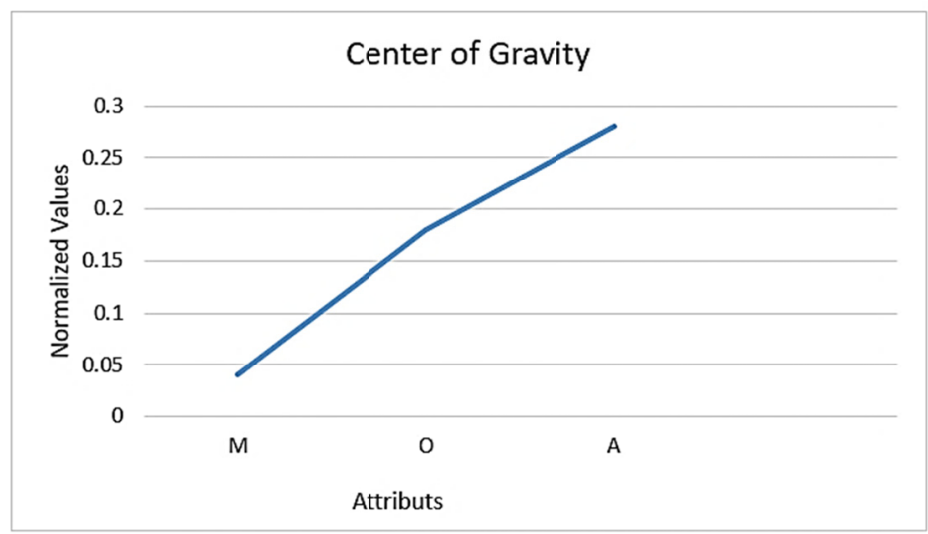

Figure 3. An example of Center of Gravity graph

After calculating the crisp number by equation (4), membership degrees to each class are computed as follows; provided that $(\mathrm{A}+\mathrm{O}+\mathrm{M})>(\mathrm{I}+\mathrm{R}+\mathrm{Q})$ holds, equations (5) to (7) are utilized in order to determine the membership degrees to classes $\mathrm{M}, \mathrm{O}$, and $\mathrm{A}$; otherwise, equations (8) and (9) are applied to discover the membership degrees.

$$
\begin{array}{lll}
\mu_{i j}=\max ((1-|C O G-1|), 0) & \text { for } & j \in\{M\} \\
\mu_{i j}=\max ((1-|C O G-2|), 0) & \text { for } & j \in\{O\}
\end{array}
$$




$$
\begin{array}{rlrl} 
& \mu_{i j}=\max ((1-|3-C O G|), 0) & \text { for } j \in\{A\} \\
\mu_{i j}=\max ((1-|C O G-1|), 0) & \text { for } j \in\{R\} \\
\mu_{i j}=\max ((1-|C O G-2|), 0) & \text { for } j \in\{I\}
\end{array}
$$

One point about the equations (5) to (9) is that, $\mu_{\mathrm{ij}}$ demonstrates to what extent parameter $\mathrm{i}_{\mathrm{th}}$ is related to class $\mathrm{j}$. 6 . In this step, using equation (10) and Table 2, the absence and presence scores of a parameter are calculated. In equation (10), $\mathrm{W}_{\mathrm{i}}$ is each parameter's weight; $\mathrm{S}_{\mathrm{kj}}$ represents the impacts of the presence and absence of a parameter so that $\mathrm{k} \varepsilon\{$ Presence,Absence $\}, \mathrm{j} \varepsilon\{\mathrm{R}, \mathrm{I}, \mathrm{M}, \mathrm{O}, \mathrm{A}\}$; and $\mu_{\mathrm{ij}}$ shows the membership degree of parameter $\mathrm{i}_{\mathrm{th}}$ to class $\mathrm{j} \varepsilon\{\mathrm{R}, \mathrm{I}, \mathrm{M}, \mathrm{O}, \mathrm{A}\}$. When $\mathrm{k}$ is absent, $\mathrm{P}_{\mathrm{ik}}$ depicts the absence score of a parameter, and when $\mathrm{k}$ is present, $\mathrm{P}_{\mathrm{ik}}$ represents the presence score of a parameter.

$$
P_{i k}=\sum_{j \epsilon J} W_{i} \times S_{k j} \times \mu_{i j}
$$

\begin{tabular}{|c|c|c|c|c|c|c|}
\hline STATE & CLASS & $\mathrm{R}$ & I & M & $\mathrm{O}$ & A \\
\hline Presence $(\checkmark)$ & & -50 & 0 & 0 & 50 & 100 \\
\hline Absence (X) & & 0 & 0 & -100 & -50 & 0 \\
\hline
\end{tabular}

Table 2. The evaluation table of Kano's model

7. Finally, by applying equation (11), the total usability score of the website is calculated:

$$
\text { Usability Score }=\sum_{\forall k, i} X_{i k} \times P_{i k}
$$

In this equation, $X_{\mathrm{ik}}$ shows whether parameter $\mathbf{i}$ is present or absent in a website, meaning that $X_{\mathrm{ik}}=1$ when $\mathrm{k}$ is present, and $X_{\mathrm{ik}}=0$ when it is absent.

\section{Implementation and Results}

First of all, some global and eminent online food ordering websites, such as Foodora GmbH (www.Foodora.com) and online sources which provide guidelines regarding website design were reviewed meticulously to identify the parameters and features of designing online food-ordering websites. Then, some experts (website designers and university professors) were asked to confirm the validity of the online questionnaire including 48 items assessing the usability of these websites that they completely confirmed its validity. Moreover, given this fact that the majority of the online food ordering websites' customers are those who are familiar with the Internet concepts and are dealing with them regularly, we chose some members of three well-known Telegram public and Iranian channels randomly and wanted them to answer our online questionnaire (Appendix A). Then, for the first step, a five level Likert scale questionnaire (Appendix A) was distributed among 30 respondents (members) to evaluate its reliability. Data were analyzed in SPSS using Cronbach's alpha which corroborated the reliability of the questionnaire (Table3).

Ultimately, 190 respondents (52.7\% female and $47.3 \%$ male) answered this questionnaire. In addition, $10.4 \%$ of the respondents had high school diploma, $48.3 \%$ had bachelor's degree, $33.8 \%$ had master's degree, and $7.5 \%$ had a $\mathrm{PhD}$. The majority of respondents were $20-29$ years old $(52.7 \%)$ and $4 \%, 29.4 \%, 9.5 \%$, and $4.5 \%$ were $10-19,30-39,40-49$, and 50 years and older, respectively. Moreover, our respondents came from different backgrounds; $27.4 \%$ were students, $29.4 \%$ were administrative officers, $24.9 \%$ were self-employed, and $18.4 \%$ had other jobs. In the demographic part, the last question was "Which device do you usually use to connect to the Internet?"; $86.1 \%, 11.9 \%$, and $2 \%$ of the respondents answered "by smart phones", "by laptops", and "by other devices", respectively. One important point is that, on average our respondents experienced more than three times online food ordering in a month. In the second part of the questionnaire, respondents declared their opinions about the presence and absence of each design parameter in food-ordering websites through functional and dysfunctional questions. Based on results, first the values of $\mathrm{M}, \mathrm{O}, \mathrm{A}, \mathrm{I}, \mathrm{Q}$ along with R and, subsequently, the weights of each parameter were calculated by the equations (1) to (3). Then, to compute the membership degrees of each parameter to each class, the normalized values were first calculated by dividing the number of responses to each class to the aggregate number of responses. After putting the normalized values on the center of gravity graph, this graph was defuzzified by the equation (4). Afterwards, using the equations (5) to (9), the membership degree of each parameter to each class was obtained. The class of each parameter according to traditional Kano model and the proposed model is demonstrated in Table 4. Subsequently, by applying the equation 10, the presence and absence scores of parameters were computed and presented in Table 5. 
Table 3. Reliability statistics for the questionnaire

\begin{tabular}{ll}
\hline Cronbach's Alpha & Number of Items \\
\hline .826 & 48 \\
\hline
\end{tabular}

\subsection{Results}

In this study, the usability of five well-known online food-ordering websites named Snappfood, Reyhoon, Chilivery, Delino, and Changal, was evaluated according to a novel fuzzy Kano method. Based on Table 6, Snappfood has the highest usability score (22.09), showing that this website is the best online food-ordering website in Iran. Snappfood is followed by, surprisingly, both Reyhoon and Chilivery with the same usability score of 10.09 , followed by Delino and Changal, both with the usability score of 7.09. On the other hand, according to Table 5, the presence and absence of some parameters have the highest impact on the usability scores of websites. For example, while the presence of parameters such as "sorting restaurants based on customer satisfaction score", and "availability of customer comments", "existence of food score", and "accessibility of website through different browsers" positively affect the usability of websites, the absence of parameters such as "using high-quality images of foods along with the image-zooming feature", "existence of complete information about foods and restaurants", and "possibility to register pre-order" negatively affect the usability of online food-ordering websites. In introduction section two questions were asked that according to the results, answers are provided here. For designing a usable online food ordering website, the following features should be taken into high consideration:

- $\quad$ Possibility to register pre-order

- Availability of customer comments

- $\quad$ Existence of food score

- $\quad$ Sorting restaurants based on customer satisfaction score

- $\quad$ Accessibility of website through different browsers

- $\quad$ Using high-quality images of foods along with the image-zooming feature

- $\quad$ Existence of complete information about foods and restaurants

On the contrary, results demonstrate that customers do not have any feelings about some features, meaning that the existence and non-existence of these features does not affect the level of customers' satisfaction. Therefore, in order to decrease the amount of information and enhance the performance, the following features could be removed:

- $\quad$ Availability of shopping without logging in

- $\quad$ Sorting restaurants based on price

- $\quad$ Purchasing in another language

- $\quad$ Saving contact information and address for future purchases

- $\quad$ Registering in website through prevalent accounts (Facebook, Google etc.)

- Sorting restaurants according to their type

- Sorting restaurants according to food type

- $\quad$ Existence of an order-tracking system

- Using videos (such as introducing restaurants), animation, and audio files on the website

\section{Discussion and Managerial Implications}

As mentioned in Results section, some parameters have specific impacts, positive or negative, on the usability score of websites. First, they strongly prefer to use an online food-ordering website which sorts restaurants based on customer satisfaction scores. Second, accessing the comments of other customers is of utmost importance to users. In addition, customers tend to include the scores of various types of foods in their decision-making process and prefer to access the website through different browsers. Moreover, users prefer to choose websites that provide high-quality images of foods equipped with the zooming feature as well as comprehensive information about foods and restaurants. One feature which is thrilling for customers is the availability of registering pre-order that except for one website (Snappfood), was neglected by all websites. Building upon these 
discussions, in the next sections we suggest some managerial implications for each website to ameliorate their designs.

Table 4. Parameters' class in conventional Kano model and the suggested fuzzy Kano model

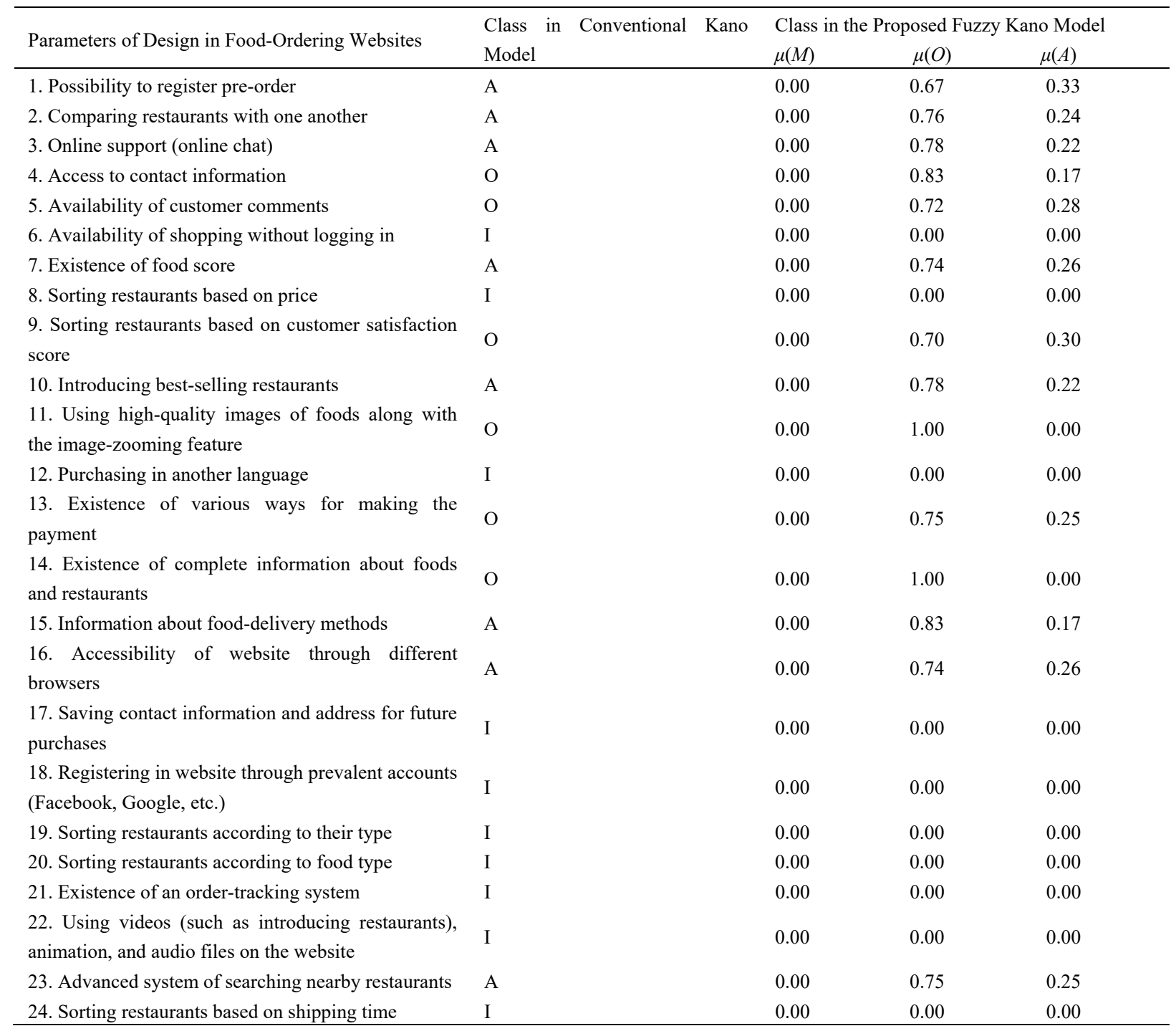

Table 5. Absence and presence scores of parameters $\left(P_{i k}\right)$

\begin{tabular}{ll}
\hline Parameters of Design & Presence and Absence Scores \\
\cline { 2 - 2 } & Presence Score Absence Score \\
\hline
\end{tabular}




\begin{tabular}{lll}
\hline 1. Possibility to register pre-order & & $\mathbf{- 1 . 3 4}$ \\
2. Comparing restaurants with one another & 1.66 & -1.14 \\
3. Online support (online chat) & 1.86 & -1.17 \\
4. Access to contact information & 1.83 & -1.245 \\
5. Availability of customer comments & 1.755 & -1.08 \\
6. Availability of shopping without logging in & $\mathbf{1 . 9 2}$ & 0.000 \\
7. Existence of food score & 0.000 & -1.11 \\
8. Sorting restaurants based on price & $\mathbf{1 . 8 9}$ & 0.000 \\
9. Sorting restaurants based on customer satisfaction score & 0.000 & -1.05 \\
10. Introducing best-selling restaurants & $\mathbf{1 . 9 5}$ & -1.17 \\
11. Using high-quality images of foods along with the image-zooming feature & 1.83 & $\mathbf{- 1 . 5}$ \\
12. Purchasing in another language & 1.5 & 0.000 \\
13. Existence of various ways for making payments & 0.000 & -1.125 \\
14. Existence of complete information about foods and restaurants & 1.875 & $\mathbf{- 1 . 5}$ \\
15. Information about food delivery methods & 1.5 & -1.245 \\
16. Accessibility of website through different browsers & 1.755 & -1.11 \\
17. Saving contact information and address for future purchases & $\mathbf{1 . 8 9}$ & 0.000 \\
18. Registering in website through prevalent accounts (Facebook, Google etc.) & 0.000 & 0.000 \\
19. Sorting restaurants according to their type & 0.000 & 0.000 \\
20. Sorting restaurants according to food type & 0.000 & 0.000 \\
21. Existence of an order-tracking system & 0.000 & 0.000 \\
22. Using videos (introducing restaurants), animation, and audio files on the website & 0.000 & 0.000 \\
23. Advanced system of searching nearby restaurants & 1.875 & -1.125 \\
24. Sorting restaurants based on shipping time & 0.000 & 0.000 \\
\hline
\end{tabular}

Table 6. Absence and presence scores of parameters (Pik)

\begin{tabular}{llllll}
\hline Parameters of Design & Online Food-Ordering Websites & & \\
\hline & Snappfood & Chilivery & Reyhoon & Delino & Changal \\
\hline 1. Possibility to register pre-order & 1.66 & -1.34 & -1.34 & -1.34 & -1.34 \\
2. Comparing restaurants with one another & -1.14 & -1.14 & -1.14 & -1.14 & -1.14 \\
3. Online support (online chat) & 1.83 & 1.83 & -1.17 & 1.83 & 1.83 \\
4. Access to contact information & 1.755 & 1.755 & 1.755 & 1.755 & 1.755 \\
5. Availability of customer comments & 1.92 & 1.92 & 1.92 & 1.92 & 1.92 \\
6.Shopping without logging in & 0.000 & 0.000 & 0.000 & 0.000 & 0.000 \\
7. Existence of food score & 1.89 & -1.11 & 1.89 & -1.11 & -1.11 \\
8. Sorting restaurants based on price & 0.000 & 0.000 & 0.000 & 0.000 & 0.000 \\
9. Sorting restaurants based on customer satisfaction score & 1.95 & 1.95 & 1.95 & -1.05 & -1.05 \\
10. Introducing best-selling restaurants & 1.83 & 1.83 & 1.83 & 1.83 & -1.17 \\
11. Using high-quality images of foods plus zooming feature & 1.5 & 1.5 & -1.5 & -1.5 & -1.5 \\
12. Purchasing in another language & 0.000 & 0.000 & 0.000 & 0.000 & 0.000 \\
13. Various ways for making payments & 1.875 & -1.125 & -1.125 & 1.875 & 1.875 \\
14. Complete information about foods and restaurants & 1.5 & 1.5 & 1.5 & 1.5 & 1.5 \\
15. Information about food delivery methods & 1.755 & -1.245 & 1.755 & -1.245 & 1.755 \\
16. Accessibility of website through different browsers & 1.89 & 1.89 & 1.89 & 1.89 & 1.89 \\
17. Saving contact information and address & 0.000 & 0.000 & 0.000 & 0.000 & 0.000 \\
18. Registering through prevalent accounts & 0.000 & 0.000 & 0.000 & 0.000 & 0.000 \\
19. Sorting restaurants according to their type & 0.000 & 0.000 & 0.000 & 0.000 & 0.000 \\
20. Sorting restaurants according to food type & 0.000 & 0.000 & 0.000 & 0.000 & 0.000 \\
21. Existence of an order-tracking system & 0.000 & 0.000 & 0.000 & 0.000 & 0.000 \\
22. Using videos, animation, and audio files on the website & 0.000 & 0.000 & 0.000 & 0.000 & 0.000 \\
23. Searching nearby restaurants & 1.875 & 1.875 & 1.875 & 1.875 & 1.875 \\
24. Sorting restaurants based on shipping time & 0.000 & 0.000 & 0.000 & 0.000 & 0.000 \\
Total & 22.09 & 10.09 & 10.09 & 7.09 & 7.09 \\
\hline
\end{tabular}

4.1 Snappfood (http://www.snappfood.ir)

According to the ranking of this article, Snappfood has the highest usability score among other online food-ordering websites, depicting its high quality. Although this website enjoys all essential characteristics, the following suggestions are made to improve its quality: 
1. Results showed that customers welcome the possibility of registering pre-order. Although Snappfood has this option at its primary levels, it would be relevant for this website to develop this characteristic more seriously, for instance, offering the registration of pre-order for longer periods, namely monthly and annually.

2. Besides, as an innovation, the managers of this website can generate the option of "comparing restaurants with one another".

3. Finally, results demonstrate that some features and options such as "sorting restaurants according to their type" and "sorting restaurants according to food type" are neutral (i.e. their presence or absence does not have any impact on website usability). Therefore, in order to improve website performance and speed, these features can be removed.

\subsection{Chilivery (https://www.chilivery.com)}

Chilivery has gained the second position in the ranking of this article. Similar to Snappfood, this website has several effective and valuable design characteristics. Nevertheless, some suggestions for improvement are presented here. First, the "existence of food score" parameter has a significant effect on customer satisfaction, a feature this website lacks. Besides, some customers like to pay the fees by cash. Unfortunately, online payment is the exclusive payment method on this website. Moreover, adding the feature of comparing restaurants with one another and preparing the system of registering pre-order could be innovative ideas in the design of this website. Finally, like Snappfood, this website can improve its speed by removing some neutral design parameters such as "sorting restaurants according to their type" and "sorting restaurants according to food type".

\subsection{Reyhoon (https://www.reyhoon.com)}

Similar to Chilivery, Reyhoon gained rank two. Although Reyhoon owns almost all design parameters with high presence scores, there is a paucity of parameters whose absence can reduce the usability of the website. Based on the results, customers tend to use websites that provide vivid and high-quality images of foods. In addition to the high quality of images, the availability of zooming feature is absolutely important for them, features which are unfortunately absent on Reyhoon website. In fact, on this website, some foods do not have images and the unavailability of image zooming has significantly affected its usability score. Other obvious points about Reyhoon are the absence of online support and payment by cash that have decreased its score. Finally, removing neutral parameters, namely "sorting restaurants according to their type" and "sorting restaurants according to food type" are recommended for website speed improvement. With respect to generating innovative ideas Reyhoon has two options:

1. Creating an option to compare the characteristics of two restaurants

2. Adding the option of registering pre-order

\subsection{Delino (https://www.delino.com)}

This website, along with Changal, received the third rank. One fundamental problem in this website which has a negative impact on its usability score is the absence of food images. In addition to the lack of zooming option, most foods in this website do not have images which is detrimental to its usability score. "Existence of food score" and "sorting restaurants based on customer satisfaction score" are parameters which are absent in Delino. To enhance its usability from the perspective of design, it would be most advisable for the managers of this website to take these parameters into account in the redesigning process. Similar to previous websites, adding "possibility to register pre-order" and "comparing restaurants with each one another" are suggested as innovative ideas.

\subsection{Changal (https://www.changal.com)}

The condition of this website is similar to that of Delino, both in ranking and missed parameters. The following suggestions are provided for boosting the usability score of this website:

1. Creating an option for customers to score different foods

2. Generating the availability of sorting restaurants based on customer satisfaction score

3. Using high-quality images of foods along with the image-zooming feature

4.Considering parameters such as "possibility to register pre-order" and "comparing restaurants with one another" as innovative ideas for redesigning in addition to removing neutral parameters

\section{Conclusion}


In the era of online shopping, the issue of website usability is highly important for e-commerce websites, especially from the perspective of design. Although previous studies have examined website usability according to various parameters, few have investigated it in terms of design parameters. In this study, by applying a method proposed by Ilbahar and Cebi (2017) which is the amalgamation of Kano model and fuzzy sets, the design parameters of five famous online food-ordering websites titled Snappfood, Chilivery, Reyhoon, Delino, and Changal were identified and classified in order to evaluate the usability score of these websites. Results revealed that the presence of some parameters such as "sorting restaurants based on customer satisfaction score" and "availability of the comments of customers" have significant effects on usability score. By contrast, the absence of parameters such as "using high-quality images of foods along with the image-zooming feature" and "existence of complete information about foods and restaurants" have detrimental impacts on usability score. Eventually, Snappfood was identified as the best online food-ordering website, followed by Chilivery and Reyhoon (both ranking second) and Changal and Delino (both ranking third).

After determining the design deficiencies of these websites using the proposed approach, some practical recommendations for improvement were offered. One of the most important findings of this study is the introduction and identification of neutral parameters whose presence or absence does not have any impact on website usability (Tables 4 and 5). By glancing over these websites, it is obvious that they are filled with a substantial number of options and characteristics that only weaken the overall performance and speed of the website. Based on the results of this study, these features are almost useless and customers do not show any tendency to use them. Accordingly, an approach to raise both the performance and the usability of websites would be removing these parameters as much as possible and Instead, managers can utilize this potential for formulating innovative ideas. Generally, the results have provided two main guidelines for the managers of these websites:

1. Improving and concentrating on features which have the highest presence or the lowest absence scores. For example, in this study feature Availability of customer comments has the highest presence score, while feature Possibility to register pre-order has one of the lowest absence scores.

2. Removing features which customers are apathetic about in order to enhance the overall website performance

However, this study has some limitations which can be ameliorated by future research. First, the number of participants can be increased in order to have a more accurate understanding about the perceptions of the public. Moreover, other aspects of usability criterion such as navigation, ease of use, and readability can be considered to assess the usability scores of online food-ordering websites by employing the proposed model. Furthermore, this approach can be utilized for other types of websites as well as the mobile applications of food ordering companies. Eventually, performing this research on websites which are globally active, including Foodpanda and Delivery Hero would be a thrilling suggestion for future scholars. Accordingly, the managers of these types of websites will be able to identify design priorities and redesign their websites based on the real expectations of customers in different countries.

\section{References}

Casaló, L., Flavián, C., \& Guinalíu, M. (2008). The role of perceived usability, reputation, satisfaction and consumer familiarity on the website loyalty formation process. Computers in Human Behavior, 24(2), 325-345. https://doi.org/10.1016/j.chb.2007.01.017

Chen, L. F. (2012). A novel approach to regression analysis for the classification of quality attributes in the Kano model: an empirical test in the food and beverage industry. Omega, 40(5), 651-659. https://doi.org/10.1016/j.omega.2011.12.004

Cyr, D., Head, M., Larios, H., \& Pan, B. (2009). Exploring Human Images in Website Design: A Multi-Method Approach. MIS Quarterly, 33(3), 539-566. https://doi.org/10.2307/20650308

Davis, D., \& Jiang, S. (2016). Usability testing of existing type 2 diabetes mellitus websites. International Journal of Medical Informatics, 92, 62-72. https://doi.org/10.1016/j.ijmedinf.2016.04.012

Díaz, J., Rusu, C., \& Collazos, C. A. (2017). Experimental validation of a set of cultural-oriented usability heuristics: e-Commerce websites evaluation. Computer Standards \& Interfaces, 50, 160-178. https://doi.org/10.1016/j.csi.2016.09.013

Florez-Lopez, R., \& Ramon-Jeronimo, J. M. (2012). Managing logistics customer service under uncertainty: An integrative fuzzy Kano framework. Information Sciences, 202, 41-57. https://doi.org/10.1016/j.ins.2012.03.004

Gonçalves, R., Rocha, T., Martins, J., Branco, F., \& Au-Yong-Oliveira, M. (2018). Evaluation of e-commerce 
websites accessibility and usability: an e-commerce platform analysis with the inclusion of blind users. Universal Access in the Information Society, 17(3), 567-583. https://doi.org/10.1007/s10209-017-0557-5

Hart, M. A. (2012). The Lean Startup: How Today's Entrepreneurs Use Continuous Innovation to Create Radically Successful Businesses Eric Ries. New York: Crown Business, 2011. 320 pages. US\$26.00. Journal of Product Innovation Management, 29(3), 508-509. https://doi.org/10.1111/j.1540-5885.2012.00920_2.x

Hirakis, E., Casey, L., \& Clough, B. (2017). Investigating Website Usability: Enhancing Engagement of Amphetamine Users in Online Treatment. International Journal of Mental Health and Addiction, 1-16. https://doi.org/10.1007/s11469-017-9796-1

Huang, Z., \& Benyoucef, M. (2014). Usability and credibility of e-government websites. Government Information Quarterly, 31(4), 584-595. https://doi.org/10.1016/j.giq.2014.07.002

Ilbahar, E., \& Cebi, S. (2017). Classification of design parameters for E-commerce websites: A novel fuzzy Kano approach. Telematics and Informatics, 34(8), 1814-1825. https://doi.org/10.1016/j.tele.2017.09.004

KANO, N. (1984). Attractive quality and must-be quality. Hinshitsu (Quality, the Journal of Japanese Society for Quality Control), 14, 39-48.

Karaim, N. A., \& Inal, Y. (2019). Usability and accessibility evaluation of Libyan government websites. Universal Access in the Information Society, 18(1), 207-216. https://doi.org/10.1007/s10209-017-0575-3

Klir, G. J., \& Yuan, B. (Eds.). (1996). Fuzzy Sets, Fuzzy Logic, and Fuzzy Systems: Selected Papers by Lotfi A. Zadeh. River Edge, NJ, USA: World Scientific Publishing Co., Inc.

Lee, Y. C., \& Huang, S. Y. (2009). A new fuzzy concept approach for Kano's model. Expert Systems with Applications, 36(3, Part 1), 4479-4484. https://doi.org/10.1016/j.eswa.2008.05.034

Legris, P., Ingham, J., \& Collerette, P. (2003). Why do people use information technology? A critical review of the technology acceptance model. Information \& Management, 40(3), 191-204. https://doi.org/10.1016/S0378-7206(01)00143-4

Li, F., \& Li, Y. (2011). Usability evaluation of e-commerce on B2C websites in China. Procedia Engineering, 15, 5299-5304. https://doi.org/10.1016/j.proeng.2011.08.982

Lin, L. Z., Yeh, H. R., \& Wang, M. C. (2015). Integration of Kano's model into FQFD for Taiwanese Ban-Doh banquet culture. Tourism Management, 46, 245-262. https://doi.org/10.1016/j.tourman.2014.05.007

Manzoor, M., Hussain, W., Sohaib, O., Hussain, F. K., \& Alkhalaf, S. (2019). Methodological investigation for enhancing the usability of university websites. Journal of Ambient Intelligence and Humanized Computing, 10(2), 531-549. https://doi.org/10.1007/s12652-018-0686-6

McCloskey, D. W. (2006). The Importance of Ease of Use, Usefulness, and Trust to Online Consumers: An Examination of the Technology Acceptance Model with Older Customers. Journal of Organizational and End User Computing (JOEUC), 18(3), 47-65. https://doi.org/10.4018/joeuc.2006070103

Menzi-Çetin, N., Alemdağ, E., Tüzün, H., \& Yıldız, M. (2017). Evaluation of a university website's usability for visually impaired students. Universal Access in the Information Society, 16(1), 151-160. https://doi.org/10.1007/s10209-015-0430-3

Moroni, I., Arruda, A., \& Araujo, K. (2015). The Design and Technological Innovation: How to Understand the Growth of Startups Companies in Competitive Business Environment. Procedia Manufacturing, 3, 2199-2204. https://doi.org/10.1016/j.promfg.2015.07.361

Nielsen, J. (1999). Designing Web Usability: The Practice of Simplicity. Thousand Oaks, CA, USA: New Riders Publishing.

Nielsen, J., \& Molich, R. (1990). Heuristic Evaluation of User Interfaces. Proceedings of the SIGCHI Conference on Human Factors in Computing Systems, 249-256._ttps://doi.org/10.1145/97243.97281

Redish, J. (1995). Are We Really Entering a Post-usability Era? SIGDOC Asterisk J. Comput. Doc., 19(1), 18-24. https://doi.org/10.1145/203586.203590

Roy, S., Pattnaik, P. K., \& Mall, R. (2014). A quantitative approach to evaluate usability of academic websites based on human perception. Egyptian Informatics Journal, 15(3), 159-167. https://doi.org/10.1016/j.eij.2014.08.002

Standardization, I. O. F. (1998). ISO 9241-11: Ergonomic Requirements for Office Work with Visual Display Terminals (VDTs): Part 11: Guidance on Usability. ISO. 
Stewart, T. (2012). Websites - Quality and Usability. Behaviour \& Information Technology, 31(7), 645-646. https://doi.org/10.1080/0144929X.2012.707372

Tung, L. L., Xu, Y., \& Tan, F. B. (2009). Attributes of Web Site Usability: A Study of Web Users with the Repertory Grid Technique. International Journal of Electronic Commerce, 13(4), 97-126. https://doi.org/10.2753/JEC1086-4415130405

Venkatesh, V., \& Agarwal, R. (2006). Turning Visitors into Customers: A Usability-Centric Perspective on Purchase Behavior in Electronic Channels. Management Science, 52(3), 367-382. https://doi.org/10.1287/mnsc.1050.0442

Venkatesh, V., Hoehle, H., \& Aljafari, R. (2017). A usability study of the obamacare website: Evaluation and recommendations. Government Information Quarterly, 34(2), 199-210. https://doi.org/10.1016/j.giq.2017.01.003

Venkatesh, V., Morris, M. G., Davis, G. B., \& Davis, F. D. (2003). User Acceptance of Information Technology: Toward a Unified View. MIS Quarterly, 27(3), 425-478. https://doi.org/10.2307/30036540

Verkijika, S. F., \& De Wet, L. (2018). A usability assessment of e-government websites in Sub-Saharan Africa. International Journal of Information Management, 20 39, https://doi.org/10.1016/j.ijinfomgt.2017.11.003

Violante, M. G., \& Vezzetti, E. (2017). Kano qualitative vs quantitative approaches: An assessment framework for products attributes analysis. Computers in Industry, 86, https://doi.org/10.1016/j.compind.2016.12.007

Wang, C.-H. (2013). Incorporating customer satisfaction into the decision-making process of product configuration: a fuzzy Kano perspective. International Journal of Production Research, 51(22), 6651-6662. https://doi.org/10.1080/00207543.2013.825742

\section{Appendix A}

\section{Questionnaire}

Feelings about the presence of a feature

1. What is your opinion about the possibility of pre-ordering?

2. What is your opinion about the feature of comparing restaurants with each other?

3. What do you think about the availability of online support (online chat)?

4. What is your opinion about the availability of contact information?

5. What do you think of the customer comment section?

6. What do you think about the possibility of purchasing without signing in to your account?

7. What do you think about the availability of the scores of a restaurant's foods?

8. What do you think of the restaurant sorting feature based on price?

9. What do you think of the restaurant sorting feature based on customer satisfaction score?

10. What do you think of introducing best-selling restaurants?

11. What do you think about the use of foods' high quality images along with magnification feature?

12. What do you think about the possibility of buying according to other languages?

13. What do you think about the possibility of paying food costs based on various methods?

14. What do you think about the possibility of accessing to complete information of a restaurant and its foods (such as ingredients)?
Feelings about the absence of a feature

1. What is your opinion about the impossibility of pre-ordering?

2. What is your opinion about the lack of the feature of comparing restaurants with each other?

3. What do you think about the lack of online support (online chat)?

4. What is your opinion about the unavailability of contact information?

5. What is your opinion about the lack of customer comments?

6. What do you about the impossibility of purchasing without signing in to your account?

7. What do you think about the unavailability of the scores of a restaurant's foods?

8. What is your opinion about the lack of restaurant sorting feature based on price?

9. What is your opinion about the lack of restaurant sorting feature based on customer satisfaction score?

10. What do you think about the non-introduction of best-selling restaurants?

11. What do you think about the non-use of foods' high quality images along with magnification feature?

12. What do you think about the impossibility of buying according to other languages?

13. What do you think about the impossibility of paying food costs based on various methods?

14. What do you think about the impossibility of accessing to complete information of a restaurant and its foods (such as 


\begin{tabular}{|c|c|}
\hline & ingredients)? \\
\hline $\begin{array}{l}\text { 15. What is your opinion about the availability of information on } \\
\text { food delivery ways? }\end{array}$ & $\begin{array}{l}\text { 15. What is your opinion about the lack of information on food } \\
\text { delivery ways? }\end{array}$ \\
\hline $\begin{array}{l}\text { 16. What is your opinion about the accessibility of website through } \\
\text { different browsers? }\end{array}$ & $\begin{array}{l}\text { 16. What is your opinion about the inaccessibility of website } \\
\text { through different browsers? }\end{array}$ \\
\hline $\begin{array}{l}\text { 17. What is your opinion about the possibility of address and contact } \\
\text { information storage for future purchases? }\end{array}$ & $\begin{array}{l}\text { 17. What is your opinion about the impossibility of address and } \\
\text { contact information storage for future purchases? }\end{array}$ \\
\hline $\begin{array}{l}\text { 18. What is your opinion about the possibility of registering on a site } \\
\text { through shared accounts like Google and Facebook? }\end{array}$ & $\begin{array}{l}\text { 18. What is your opinion about the impossibility of registering } \\
\text { on a site through shared accounts like Google and Facebook? }\end{array}$ \\
\hline $\begin{array}{l}\text { 19. What is your opinion about the sorting feature based on the type } \\
\text { of restaurant? }\end{array}$ & $\begin{array}{l}\text { 19. What is your opinion about the lack of sorting feature based } \\
\text { on the type of restaurant? }\end{array}$ \\
\hline $\begin{array}{l}\text { 20. What is your opinion about the restaurant sorting feature based } \\
\text { on the type of food? }\end{array}$ & $\begin{array}{l}\text { 20. What is your opinion about the lack of restaurant sorting } \\
\text { feature based on the type of food? }\end{array}$ \\
\hline $\begin{array}{l}\text { 21. What do you think about the existence of an integrated tracking } \\
\text { system on the website? }\end{array}$ & $\begin{array}{l}\text { 21. What is your opinion about the lack of an integrated } \\
\text { tracking system on the website? }\end{array}$ \\
\hline $\begin{array}{l}\text { 22. What do you think about the use of video (such as restaurant } \\
\text { introductions), animation and attractive audio files on website? }\end{array}$ & $\begin{array}{l}\text { 22. What do you think about the non-use of video (such as } \\
\text { restaurant introductions), animation and attractive audio files on } \\
\text { website? }\end{array}$ \\
\hline $\begin{array}{l}\text { 23. What do you think of the availability of an advanced search } \\
\text { engine for nearby restaurants? }\end{array}$ & $\begin{array}{l}\text { 23. What do you think of the unavailability of an advanced } \\
\text { search engine for nearby restaurants? }\end{array}$ \\
\hline $\begin{array}{l}\text { 24. What do you think about the lack of restaurant sorting feature } \\
\text { based on the shipping time? }\end{array}$ & $\begin{array}{l}\text { 24. What do you think about the lack of restaurant sorting } \\
\text { feature based on the shipping time? }\end{array}$ \\
\hline
\end{tabular}

\section{Copyrights}

Copyright for this article is retained by the author(s), with first publication rights granted to the journal.

This is an open-access article distributed under the terms and conditions of the Creative Commons Attribution license (http://creativecommons.org/licenses/by/4.0/). 